\title{
The Structure Research of the Independence and Control C4ISR System
}

\author{
Cao Wei, He Xinhua, Fan Xiquan, Zhou Diansu \\ Department of equipment Command and Administration Beijing
}

\begin{abstract}
Independence and control is the trend of the our army C4ISR future development .The paper introduced the definition of the C4ISR architecture, analysis the conception about the freedom and controlled and importance to the C4ISR.The major design methods of C4ISR architecture research are summarized .Finally, the paper analysis infection that is the freedom and controlled C4ISR to the design of the C4ISR architecture.
\end{abstract}

\section{Keywords-independence and control,C4ISR, architecture}

\section{INTRODUCTION}

The information technique is in the military realm of extensive application, caused the root of the military theories, battle style and war appearance variety, urge to born to change into core by information of new military change. New military change of the foundation will be a weapon material based of information. See through the end of 20 centuries to the beginning of 21 centuries , world scope occurrence of several high technique limited war, weapon material based of information technique manifestation it huge potential. The electronics information of the weapon material content has already become importance marking of measure its function and modernization level[1]

The military equipment based information extensively applied, the C4ISR will face more and more problems with safe information. The basic reason is the independence level of the important system, core technique and key equipments not high, become a bottleneck to C4 ISR safety. The basic reason is the independence level of the important system , core technique and key equipments not high, become a bottleneck to C4 ISR safety the of the guarantee. The total secretary of $\mathrm{Hu}$ Jintao once pointed out : BE relating to national economy and the key realm of national security, real core technique and key technique only can depend on ourselves, only can depend on independence innovation".

\section{THE CONTROL AND INDEPENDENCE C4ISR}

A. The problems that consist in C4ISR that controlled and independence

1)

\section{system can not update smoothly}

The information processing equipments of the information system invests scale huge, the operate system, network, operate system all most buy a foreign mainstream products. These foreign products with no independent intelligent property right complications operate complexly, technique data missing, and can hardly for local customer to make secondly developments. To the dependence degree of the foreign information tycoon greatly, if they don't provide software update service, our systems then are always subjected to monopoly to the information system core technical.

\section{2) Existence of fatal information safe loophole}

No matter what a chip or a software code in the information system, if isn't independence development, we can not get hold of a core technique. The foreign manufacturer usually can't provide a core technique to the local customers, therefore the local customer is very difficult to completely examine the reliability and charge of the equipments. We can not promise that it doesn't transplant a malice code, breaks through malice back door and join concealment instruction in the process of the design 、 update, maintenance of information product, but in fact these threats are really existence. Once these loopholes are used to implementation attack, invade, modify, malicious damage or steal a confidential data information, our national security and national defense will be influenced.

\section{B. The concept analysis of the independence and control}

The independence and control, the independence is first, then can attain real can control, then carry out an overall safety, the independence is to control of essential condition. The independence is the military information system construction act on our own. The independence can not simply comprehend localization, currently a lot of products of domestic still rely on foreign core technical, the core technical of this kind of localization is not control in ourselves hand. It is a fake independence, still existence factor that is not control, safety hidden trouble still existence. The real independence is that have can control and modify existing product and technique, have the ability complete independence development, completely possess our own intellectual property and can have the ability to control product and technical development. The independence and control of the military information system must build up in this real independence.

From the narrow sense, the independence and control of the military information system mainly is technical related military information system product independence can control, that is in the system construct, use software, hardware and technique that have the independence intellectual property, this is the foundation of the military information system independence and control.From the broad sense, the independence and control of the military information system should cover a military information system construction development, each link all independence and control, not simply use the product that 
the independence can control, then can construct complete safe system of the military information system.

\section{The independence and control is the future development of the C4ISR}

Weapon information is rely on the information industry. The information industry of our country is total up still in the primary stage, in many large C4ISR system, a great deal of infrastructure, CPU of computer, operate system, router and big parts of key equipments of high level server and so on rely on import. The key technique and product under the yoke of others, the ability of independence and control is not strong, this equivalently place our own secret to the other people's eyelid underneath, this kind of phenomenon brings greatly suffer to the national defense safety of our country.

The information technique particularly the core part of technical information if that is no independent information technique, we will lose our own international society stabilize, safety of active power[2].National defense science and technology university president, Zhang Yu Lin, says that "only strongly create the information system that have the independence and control, then it can ensure the information is safe and ensure the information construction have a solid foundation."

Currently, all countries put the weapon information to strategic layer, and pass independence develop, buy and reform etc. way to strongly promote weapon information level. The information equipment should prior choose the information equipment that is the independence and control. The independence of the equipments is not simple understand localization, a lot of products of the national product still stay around assembling foreign core technique, the core technique doesn't control in ourselves hand. The real independence and control should be the key component independence, operate system independence, software independence, each links all independence to control[3].Then it can construct integrated, independence and control of C4ISR system structure.

\section{THE STRUCTURE DESIGN OF INDEPENDENCE AND CONTROL C4ISR SYSTEM}

\section{A. The design frame of the C4ISR system structure}

The system structure frame is the norm of system structure description and ensure that the comprehension toward the system structure, comparison and integration to an united standard.C4ISR system structure frame is composed of four parts: the definition, the product description, general reference resources and system structure and that is provide a design and express method of the C4ISR system structure. C4ISR system structure frame is composed of battle system view, system structure view and technique system view, such as figure 1 show, respectively from battle demand and application, system design and technique three angle of views to describe C4ISR system structure [4]. Battle architecture mainly description battle concept and battle item, battle unit, battle information etc. and their relations. The system architecture via the exploitation of the physical resources to ensure battle task and the completion of the action in battle, mainly description inter-correlation of provides or supports battle function. The technique architecture is a set of rule that determine the system constitutes elemental organization and correlation. These three kinds of system architecture provided together with each other allied, mutual communication, operation. relationship shown as figure 1 .

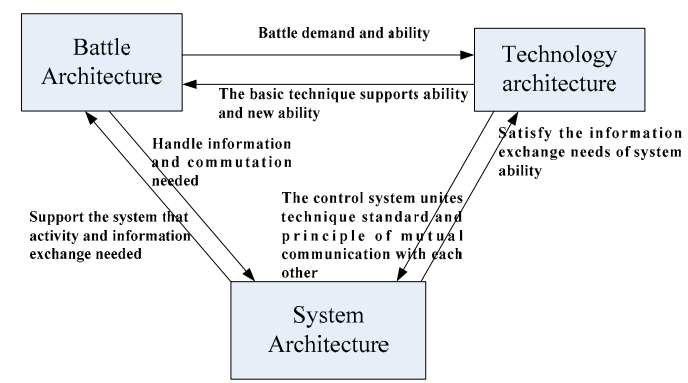

Figure 1.diagraml relationship between architecture

\section{B. The general design method of the C4ISR architecture}

The architecture design method mainly according to architecture frame, with the system develop methodology (such as structure analysis, faces to object...etc.) as instruction. The architecture design method, get the procession of the architecture describes fit the frame. Architecture design method development was main to experience from face to process to face to object again develop according to the process of method of activity. Face to the process such as structure analytical method, put forward six processing processes to the product, finally get all architecture product view. The face to object method is a kind of system analysis and design method, such as unify the method of model language(UML). Face to the object method with the easily support and code reuse advantage characteristic, get more and more applications in the development of complicated system. These two kinds of methods are mainly research design architecture product according to what about step, method, adoption what about model, put attention in how design each architecture product, but not research the relation of concrete product.

Along with the C4ISR system is more and more complicated and demand the system integration, operate with each other more and more high, the norm of architecture design method turn important day by day. The American Ministry of National Defense releases in December, 1997 《C4ISR architecture frame $2.0 》$, forward a kind of standardize method used for architecture development and express, named three dimensional method. Its purpose is " establishment simplex, unify of Ministry of National Defense technique "[5], control and norm all C4ISR the development. See from the total up, the development process of architecture design method, reflect 
the complicated degree, integration of the system to turn more and more high, also reflect the demand to the ability of operate with each other to the system more and more strict.

\section{The influence that is The independence and control C4ISR to architecture design}

The technique standard view give out technique standard to the system realization, is the foundation to construction an engineering technical specification. The purpose that draws up technique standard view is provides the establishment engineering specification, constructs an general module and develop a product production line judging by guidebook. The technique standard view contain two kinds views, one is technique standard system(TV1),the other is technique standard predict (TV-2).

The independence and control information system will rely on important military information system engineering, speed industry technique standard system construction, perfect the technical specification and criterion, such as technique system and product...etc. of the information technique application, promote the system mutual communication with each other, operation with each other and information share. The information technique foundation of our country is weak, the key part of information technique equipments mainly is foreign, we short of controllable technique and standard. If the information standard of our country can not keep independent, and there is no our own standard system and have no information safety guarantee of information-based isn't a real meaning of information-based. Information safety's standardizing is an foundation guarantee to information safety construction and the system circulate. So to strengthen an information safe standard system research, to perfect information safe standard system suitable our country.

The independence and control information system will gather together everyone's advantage and push forward applied norm and technique standard draft, prior to use the standard of having the independent intelligent property right, promote the status of the independence and control information standard at the nations [7].

Today, the big military country construction practice show, make use of the comprehensive integration method to construct integration military system, have already become the basic path that construct information-based troops. However carry out the comprehensive integration of system, have to depend on standard to unify a technique system, form layer designs, build up the best order and carry out whole superior, raise the whole battle effect of system completely. Develop the information standard system research that fit for our country state, draw up our country the development programming of the information standard. It can provide guidebook for our army information technique standard system construction and forecast information standard.

\section{SUMMARIES}

The architecture design is an importance component of system top layer design and is the key integration of the C4ISR system. C4ISR develop an important function in the modern information war, the good and bad of its function directly influences to obtain information advantage and occupy battle advantage, raises the information system fight power. carrying out the independence and control of information system, enhance the independent innovation of foundation software and core device, and control a batch of cores technique in our hard. No matter under what circumstance, the life vein of information-based construction should control in the ourselves hand.

The high military technology, as the most important fighting strength, it not only cause the change of war style and battle method, and pushed a turning into of military strategy. The high military technology bring out the opportunity and challenge to our national defense, we should promote the development of the national defense science and technology industry, independent innovation, continuously strengthen the foundation construction of military change in national defense. The fact proves: the independence and control high military technology used in battle system, can cause the change of war style and battle method, and push military evolution.

\section{REFERENCES}

[1] Wang Ya Mei. Stereo-development of our army information-based equipment 【 J 】.The journal of the Academy of Equipment Command \& Technology, 2007, 18 (5):19-22.

[2] Ni guang nan.Electronics governmental affairs construction should according to the native soft hardware 【J 】 .Information-based study, 2006:11-12

[3] Speed industry development, carrying out the independence and control 【J】 computer safety, 2004,(4):457-458.

[4] C4ISR construction frame(2.0 editions)

[5] DoD Architecture coordination counc, C4ISR Architecture Framework Version[M]2. O. 1997.

[6] Xiao hui xin, Wang Jing Bin, Peng xiao long. The apocalypse of the outside soldier weapon equipment information-based development in 21 th century to our army 【J】.Strategic forum, 2006, (3): 1720.

[7] Cai Hong.Construct independence and control information safety guarantee system with all strength 【J】.Information safety and correspondence keep secret, 2004, (5) 